\title{
News from Italy
}

On the invitation of the Austrian Society for Literature (Osterreichische Gesellschaft für Literatur), Claudio Magris, cf the University of Trieste, read a paper on the present perspectives of "Central European Literature" at the Palffy Palace, in Vienna, on April 4, 1968. He talked on the same topic at the Free University of Berlin in May, 1968. In March, 1970, he lectured at the University of Paris and at the Austrian Cultural Institute at London on "Joseph Roth between Empire and Golem."

The forty-fourth congress of the Italian Institute for the History of the Risorgimento was held at Trieste on October 31-November 4, 1968. Papers dealing with Austrian or AustroItalian history were read by the late Carlo Schiffrer, of the University of Trieste, on public opinion in Trieste during World War I; by Manlio Udina, of the University of Trieste, on the problems of international law raised at the Paris Peace Conference; and by Fritz Fellner, of the University of Salzburg, on the relations between Austria and the Successor States.

On November 30, 1968, Friedrich Engel-Janosi, of the University of Vienna, delivered a paper dealing with the personal reminiscences of an Austrian officer at the Italian front during World War I at the Museum of the Risorgimento, in Milan.

Two symposia dealing with Austrian literature were sponsored by the Institute for German Studies at the Villa Sciarra in Rome. At the first one, held in January, 1969, three papers on "Young Vienna" ("Jung Wien") were presented by Paolo Chiarini, Giuseppe Farese, and Friedbert Aspitzberger. The second symposium, which was devoted to Adalbert Stifter, took place in January, 1970. Paolo Chiarini, Marino Freschi, Claudio Magris, Walter Weiss, and Luciano Zagari analyzed and discussed various aspects of Stifter's personality.

On March 12, 1969, Adam Wandruszka, of the University of Vienna, talked in Florence on Peter Leopold of HabsburgLorraine. His lecture was sponsored by the local committee of the Society for the History of the Risorgimento. 
On the occasion of the formal opening of a special Lajos Kossuth room in the National Museum of the Risorgimento at Turin on May 8, 1969, Péter Hanák, of the Hungarian Academy of Sciences, delivered a lecture on the relations between Kossuth and the Italian national movement during the Risorgimento.

Milan

ANGELO ARA 